\title{
O ÊRRO EM MATÉRIA PENAL
}

\section{Ernani Cabral de Loyola Fagundes}

Professor da Faculdade de Direito de Goiás

O magistrado cônscio de seus deveres, tratando de apurar a responsabilidade em matéria criminal, deverá olhar, antes de proferir qualquer sentença, para o interêsse social. Nos Estados Unidos da América do Norte êste princípio é cânone da jurisprudência porque, se os magistrados resolvem os casos individuais, suas sentenças devem ser orientadas no sentido de estabelecerem o equilíbrio social, finalidade precípua do direito. A decisão refere-se a um caso concreto, mas deve ter um escôpo de ordem geral. A pena é a expressão da justiça pública mas também a manifestação de auto-defesa do Estado, que necessita cuidar de seu organismo, de que a coletividade faz parte.

O criminoso é um doente, um inadaptado à ordem social, como diz Vaccaro, devendo ser tratado dentro de normas científicas e com humanidade. Mas é também um sêr nocivo, perigoso à paz coletiva.

Entendemos que o juiz deve vivificar a lei, tornando-a eficiente a fim a que se destina.

A norma jurídica não é um preceito estático, sujeito apenas à interpretação literal. $\mathbf{E}$ preciso tirar da letra que mata o espírito que vivifica, como afirmou São Paulo, na Segunda Epístola aos Coríntios. É imprescindível aplicá-la de tal sorte, que sirva ao delinquente, mas também à sociedade, na justeza de seu conteúdo e no desideratum acertado da sanção. 
É natural que o crimirioso seja segregado do convívio de seus concidadãos, porque êle é um indivíduo temível à ordem pública, capaz de reincidir, de pôr novamente em perigo a vida ou a propriedade de seu semelhante, como qualquer outro direito, não menos digno da proteção do Estado.

Todavia, casos há em que a pessoa lesa o direito alheio, mas sua responsabilidade é excusável, dirimida ou justificada.

É conveniente que façamos a leitura dos arst. 16,17 e seus parágrafos. do Código Penal, e que assim precsrevem:

"Art. 16 - A ignorância ou a errada compreensão da lei não eximem de pena.

"Ar. 17 - É isento de pena quem comete o crime por êrro quanto ao fato que o constitui, ou quem, por êrro plenamente justificado pelas circunstâncias, supõe situação de fato que, se existisse, tornaria a ação legítima.

“§ $10^{\circ}$ - Não há isenção de culpa quando o êrro deriva de culpa e o fato é punível como crime culposo.

"§ $2 .^{\circ}$ - Responde pelo crime o terceiro que determina o êrro.

"§ $3 .^{\circ}$ - O êrro quanto à pessoa contra a qual o crime é praticado, não isenta de pena. Não se consideram, neste caso, as condições ou qualidades da vítima, senão as da pessoa contra quem o agente queria praticar o crime".

Consoante Jimenez de Asua frisa, em sua interessante monografia El Error de Derecho em Materia Penal, "há uma fuandamental distinção entre a ignorância e o êrro, já apontada por Platão. A primeira supõe a falta de conhecimento ou de qualquer representação e consiste na ausência total da noção sobre um determinado objeto: é um estado negativo. 0 êrro supõe uma idéia falsa, uma representação errônea de um objeto certo: é um estado positivo. A ignorância, em suma, consiste na falta completa do conhecimento,enquanto que no êrro há um conhecimento falso".

Mas em matéria jurídico-penal, ignorância e êrro se equivalem e ninguém pode ser isento de responsabilidade criminal 
pelo fato de ignorar a lei ou de fazer um falso juizo de seu conteúdo.

José Frederico Marques, ilustre magistrado e professor paulista, em sua recente obra "Curso de Direito Penal", ensina :

Êrro e ignorância, no campo do Direito Penal, têm o mesmo significado. Equiparam-se no campo da relevância jurídica. Sob a velha parêmia - nemo ius ignorare censetur - tanto está a ignorar a lei como a errar a respeito da lei. Da mesma forma que na outra máxima error juris semper nocet - tanto se compreende o êrro de direito como a ignorância da lei. 0 princípio ignorantia legis non excusat é base indispensável de todo o ordenamento jurídico-penal".

O ministro Nelson Hungria, em seus "Comentários ao Código Penal”, vol. I, pags. 382 e 383, esclarece:

"No art. 16, o Código declara irrelevantes a ignorância da lei (desconhecimento da existência da lei) ou o êrro de direito (errada compreensão da lei), colocando-os em pé de igualdade. Práticamente, tanto faz a ausência total do conhecimento (ignorância), quanto o conhecimento desconforme da realidade (êrro). Não há porque distinguir, para diverso tratamento jurídico, entre o nenhum e falso conhecimento da lei, entre a ignorantia legis e o error juris, entre o não conhecer e o conhecer mal a normal legal. A ignorantia legis não deixa de ser um error juris em sentido lato, pois vale o mesmo que falsa conviç̧ão de inexistência da lei. Não há, portanto, inconveniente ou impropriedade de técnica com o empregar-se na espécie, em carater genérico, a expressão "erro de direito"”.

"O Código vigente permaneceu fiel ao princípio tradicional de que error juris nocet, e sómente condescende em atribuir ao êrro de direito, quando excusável, influência atenuadora da pena (art. 48, III). 
Entretanto, em matéria de contravenções penais, admitese o êrro de direito como causa excludente da imputabilidade. É o que preceitua o art. $8 .^{\circ}$ do decreto-lei n. 3.688 , de 3 de outubro de 1941:

"No caso de ignorância ou de errada compreensão da lei, quando excusáveis, a pena pode deixar de ser aplicada".

Comentando o art. supra, o ministro Bento de Faria, em seu conhecido livro "Das Contravenções Penais", à pag. 47, confessa :

"Inclino-me ao critério, geralmente aceito na doutrina alemã, que não estabelece distinção entre o êrro de fato e o êrro de direito, porque se trata sempre de êrro com referência às circunstâncias objetivas do fato.

"Assim, se o êrro e a ignorância, realmente constatados, não forem impuáveis ao agente, não sendo determinados por descuido ou negligência, devem ser considerados como causa excludentes da criminalidade".

E na página seguinte, tratando mais detidamente da ignorância quanto ás contravenções, cujo elemento moral, como diz o ministro Francisco Campos, na Exposição de Motivos da lei, repousa na simples voluntariedade da ação ou omissão, prescindindo-se do dolo ou da culpa, afirma ainda Bento de Faria:

"Se a lei nova, por exemplo, pune fatos que anteriormente escaparam à sua sanção, e o agente não podia $a b-$ solutamente conhecê-la, ou por se achar em país estrangeiro ou retido fora do território nacional, tendo ocorrido a interrupção de comunicações, seria injusto torná-lo responsável pela infração".

Quanto à errada compreensão da lei em matéria de contravenções, doutrina ainda aquêle conhecido e saudoso jurista:

"No sentido explicativo da Exposição de Motivos, tal pode ocorrer quando, por evidente rusticidade do agente, isto é, quando se trata de indivíduo inculto, estúpido, é equiparável à ignorância. 
"Não pode compreender mal a lei quem a desconhece; e quando conhecendo-a, interpreta mal - erra em sua compreensão".

E Bento de Faria conclui: "a escusa, com tal fundamento, deve ser admitida por não se verificar a livre determinação da vontade".

Interessante foi a decisão do Supremo Tribunal Federal, inserta na revista "O Direito", vol. 82, pag. 510, afirmando que o caso controvertido exclui a responsabilidade criminal.

Mas sem dúvida, o texto do art. $8 .^{\circ}$ da Lei das Contravenções, que acima comentamos, difere, substancialmente, do art. 16 do Código Penal, o qual torna bem expresso que a ignorância ou o êrro de direito não exime de pena o delinquente.

Contudo, talvez para provar que não há princípio absoluto, o prof. Basileu Garcia, da Faculdade de Direito da Universidade de São Paulo, em suas "Instituições de Direito Penal", vol. I, pags. 276 e 277, aborda a questão do êrro de direito extrapenal, o que também é digno de registo:

"A assertiva de que o êrro de direito não excusa, diz êle, prende-se ao Direito Penal. É irrelevante ignorar o agente, por exemplo, que a apropriação indébita constitui crime. Mas o êrro sôbre o Direito extrapenal (Civil, Administrativo etc.), considera-se êrro de fato. Se o agente, em virtude de errôneo entendimento de uma relação jurídica, conserva como sua a coisa alheia, incide em êrro de direito extrapenal, equivalente a erro de fato e não poderá ser condenado por apropriação indébita. A Exposição de motivos apresenta um tópico que parece desautorizar essa conclusão, a qual, no entanto, prevalece na melhor doutrina, em meio a largos debates.

"Parece-nos, verbi gratia, inconcebível se declare responsável por crime assimilado ao de moeda falsa a pessoa que, como na hipótese de Carrara, ao regressar ao território nacional, de onde se ausentara durante certo tempo, passou, de boa fé, cédulas cujo recolhimento fôra ordenado por intercorrente lei. Com razão proclamou o 
mestre de Pisa (Opuscoli, $7 .^{\circ}$ vol., pag. 391): "sarebbe iniquità condannarlo alla pena".

"O brocardo ignorantia legis non excusat, corporificando uma ficção, manda às vêzes punir o verdadeiramente inocente, o que repugna ao senso de justiça. Ele afrônta o princípio de culpabilidade. Convem aceitar as atenuações que tolera, e uma bem razoável é a eximente influência do êrro de direito extrapenal, quando conduza o êrro sôbre elemento de fato da infração".

Entretanto, Francisco Campos pensa em sentido contrário, pois em sua Exposição de Motivos, diz o seguinte:

"O projeto não faz distinção entre êrro penal e erro de direito extrapenal: quando uma norma penal fez remissão a uma norma não penal ou a pressupõe, esta fica fazendo parte integrante daquela e, consequentemente, o êrro a seu respeito é um irrelevante error juris criminalis".

Nelson Hungria é do mesmo parecer; pensar em sentido contrário, diz êle, "seria abrir larga brecha no princípio político-jurídico-penal do error juris nocet. 0 ministro Campos não fez mais do que repetir uma noção corriqueira na doutrina penal moderna. Cita autores alemães e italianos em abono dessa assertiva e conclui, repetindo Massari:

"Deve-se considerar, como regra geral, que o dever peremptório do conhecimento abrange, não apenas 0 praeceptum juris (esteja inserto no Código Penal ou em outras leis penais gerais ou especiais ou no corpo de leis não penais), mas também todas as várias normas que, em função de esclarecimento, de pressuposto, de elemento constitutivo do crime, acedem ao praeceptum juris, sejam elas de direito civil, administrativo etc., derivadas da lei ou do direito costumeiro. Na verdade, tais normas, pelo fato de que acedem ao praeceptum juris, concorrem tôdas na formação da norma penal, e tôdas têm, em relação a esta, valor essencialmente construtivo; de modo que, quando a elas, deve ter aplicação o princípio nemo censetur ignorare legem". 
Nelson Hungria e Frederico Marques ainda falam sôbre o delito putativo, como consequência de um êrro de direito, e que Antolisei denominou de "não crime" ou delito puramente imaginário. Por exemplo, o indivíduo que, no Brasil, deflora mulher de mais de 18 anos e que fica preocupada com o fato, supondo que praticou um crime. Mas se é um delito imaginário, não pode ser chamado "delito putativo", pois não existe como figura criminal; é apenas fruto do êrro ou da ignorância subjetiva, sem consequências de ordem penal. Não havendo delito, por falta de um dos elementos integrantes, a nosso ver, não é de se falar em crime putativo, já que a infração penal existe ou não existe, pois uma coisa não pode ser e deixar de ser ao mesmo tempo, consoante a lógica nos ensina. Alguns juristas esmiuçam demais os institutos e acabam criando, num casuismo escolástico, figuras de delitos inexistentes...

Mas passemos a apreciar o art. 17 e seus parágrafos, do Código Penal.

Façamos agora um estudo bem circunstanciado sôbre o êrro de fato, porque o assunto é assaz importante no terreno da imputabilidade criminal.

Conforme ensina Basileu Garcia, a cuja cultura e espírito didático queremos render nossa homenagem, "o êrro de fato pode ser essencial e acidental. É essencial, quando versa sôbre elemento constitutivo da infração, de tal forma que o erime não se verificaria, se não fôra o êrro. É acidental quando incide sôbre aspecto acessório, secundário, de modo que o crime se verificaria, mesmo sem o êrro, e com êle apenas se modifica na sua concreta manifestação.

"Exemplificando: alguém detona a arma de fogo contra um vulto, na certeza de se tratar de perigoso animal. Vem a ferir e matar um homem. Pratica homicídio. É obvio que, nessa hipótese, não existe o dolo e, se também não houve imprudência por. parte do agente, êle não é responsável pelo homicídio. $O$ êrro é tal, que se tornou inexistente o crime, pela carência de causalidade subjetiva. Versa sôbre elemento indispensável à configuração do fato criminoso, pois o agente não 
teria detonado a arma, se soubesse estar ante uma criatura humana. 0 êrro essencial exclui o dolo. Quem age nessas condições não procede com vontade consciente.

"Alguém se apossa de objeto pertencente a outra pessoa, mas assim procede na convicção de que é seu. Não incorre em crime de apropriação indébita, por lhe faltar a vontade consciente de se apoderar de coisa alheia.

"Uma pessoa casa-se com outra, já casada. As leis penais punem a quem, por essa forma decisiva, coopera para a prática do crime de bigamia. Mas tal pessoa não sabe da existência do casamento anterior. Procede por fôrça de êrro essencial.

"É evidente, em cada um dêsses casos, que o dolo não existe, mas é o êrro que lhe imprime a inexistência.

"Exemplo de êrro acidental: o caso de um indivíduo que subtrai objeto de A, supondo ser de B. Está procedendo com êrro, também, mas o êrro não altera substancialmente o fato, não elimina a criminalidade. Ou furta farinha, imaginando que é açúcar. 0 êrro, nesses casos, diz respeito á circunstância secundária da infração. Pouco se dá que o objeto seja de A ou $\mathrm{B}$, pois é certo que não pertence ao agente; e não importa a sua natureza: integra-se a figura delituosa do furto".

José Frederico Marques doutrina a respeito, em sua referida obra:

"O êrro de fato exclui a culpabilidade, sempre que incida sôbre o fato constitutivo do crime, ou sôbre um dos elementos dêste, pois em consequência do êrro a vontade não se determina de forma normal. "Não há possibilidade, diz Bettiol, de uma determinação sôbre aquilo que se realizou e que não se devia praticar, porquanto o êrro de fato é ignorância ou falsa representação da realidade. 0 evento realizado não é, de nenhum modo, intencional".

"Em face do êrro sôbre o fato, o agente delibera e age sob uma falsa impressão da realidade. Ele atua, assim, de "boa-fé", certo de não estar atentando contra a lei penal, ou na persuasão de encontrar-se no exercício de 
um direito que a ordem jurídica lhe reconhece. Daí a regra do art. 17, do Código Penal: É isento de pena quem comete o crime por êrro quanto ao fato que o constitui, ou quem, por êrro plenamente junstificado pelas circunstâncias, supõe situação de fato que, se existisse, tornaria a ação legítima.

"Se o indivíduo atira sôbre um objeto que ao longe se move, na persuasão de estar alvejando uma caça, e atinge, porém, um homem, pode ter havido êrro de fato pertinente a elemento constitutivo da figura típica da lesão corporal: o agente não pretendia violar a lei penal, ferindo alguém, pois atirou por acreditar que se tratava de algum animal.

"Cumpre advertir, como lembra Nélson Hungria, "que muitas vêzes o êrro sôbre circunstância essencial de determinado crime não exclui a punibilidade por crime diverso (ex.: o indivíduo que dirige impropérios a outro ,ignorando que êste é funcionário público in officio, não comete o crime de desacato, mas o de simples injúria). Com maioria de razão, o êrro sôbre circunstância qualificativa não isenta de pena pelo tipo fundamental do crime (aquêle que favorece a prostituição da própria filha, mas inciente dessa sua qualidade, não é punível por lenocínium qualificatum, mas por lenocínio simples)".

"Como o êrro de fato diz respeito à falsa representação de um elemento do crime perpetrado, deve êle impedir que o agente saiba que sua conduta é enquadrável numa figura típica descrita na lei penal. Daí se segue que o êrro sôbre circunstância do crime, condições de punibilidade e outros elementos não essenciais - é de todo irrelevante como causa excludente da culpabilidade. 0 êrro que produz efeitos jurídicos, ensina Antolisei, é o que se relaciona "com os elementos essenciais dos diversos crimes. Se, portanto, o êrro se refere a elementos ou circonstancias de outro gênero, é irrelevante em relação à vontade culpável. Assim, nenhuma eficácia, para tais fins, pode encontrar-se num êrro de um homicida 
que, crendo usar poderoso suporífero, empregue ao revés a estriquinina".

Mas o êrro de fato para que seja essencial, é preciso que seja invencível, inevitável, e que o agente não se tenha conduzido com imprudencia, negligência ou imperícia, pois, neste caso, pune-se o delito como culposo, de conformidade com o $\S 1 .^{\circ}$ do art. 17 do C. Penal.

Enrico Altavilha, em seu livro La Colpa, ed de 1950, pag. 198, como exemplos de êrro culposo, cita os seguintes casos:

"No ordenar o sepultamento de um indivíduo em estado de catalepsia, não respeitou o médico aos preceitos de polícia mortuária; alguém subministra a um familiar o arsênico, em lugar do bicarbonato, porque não leu a etiqueta da farmácia; o caçador feriu o menino, tomando-o por um "espantalho", enquanto se fôsse mais atento, teria podido ter conhecimento exato da realidade, corrigindo sua erronea percepção".

Já noutro aspecto, o êrro é invencível, consoante o ensinamento de Nélson Hungria, "quando não podia ser evitado com a atenção, ponderação, perspicácia ou diligência ordinária, própria do comum dos homens. No aferir-se a invencibilidade do êrro, tem-se de adotar o mesmo critério objetivo de reconhecimento da imprevisibilidade, na órbita da culpa strito sensu. Deve ter-se em conta, como paradigma, o tipo psicológico médio, e não o agente em função de si mesmo, apreciado na sua conduta habitual, ou segundo seu maior ou menor poder de atenção, sua maior ou menor impressionabilidade. Tem-se de figurar a situação de fato ou o conjunto de circunstâncias objetivas em que ocorreu o êrro e indagar como teria procedido o homem de tipo comum ou normal: se não se depara desconformidade alguma, o êrro deve ser considerado invencivel (impediente de qualquer culpabilidade); caso contrário, será declarado vencivel, excluindo a culpabilidade a título de dolo, mas não a título de culpa em sentido estrito. 
"A teoria do êrro de fato, como diz M. E. Mayer, não é mais do que o reverso da teoria da culpabilidade ou a própria teoria da culpabilidade considerada "de um ponto de vista negativo". Viciando o processo psicológico, o error facti cria representações ou motivos que determinam uma conduta diversa da que o agente teria seguido, se tivesse conhecido a realidade. A sua relevância jurídico-penal assenta num princípio central da teoria da culpabilidade: non rei veritas, sed rerum opinio inspicitur.

A ignorantia facti, quando insuperável, acarreta uma atitude psíquica oposta à da culpabilidade, isto é, falta da consciência da injuricidade (que, como já vimos não tem nada a ver com a obrigatória sciencia legis, não é reconhecivel o dolo, e desde que inexiste até mesmo a possibilidade de reconhecer a ilicitude da ação (ou omissão), entra-se no domínio do caso fortuito. Não pode ser reconhecido culpado o agente, quando lhe era impossível cuidar que estava incorrendo no juízo de reprova$c ̧ \tilde{a} o$ que informa o preceito incriminador. A inevitabilidade do êrro coincide com a impossibilidade de ciência da injuridicidade e, portanto, com a ausência de qualquer das formas de culpabilidade.

" $E$ bem de ver que o êrro deve ser tal - conclui Nélson Hungria - que acarrete a sincera persuasão, a certeza subjetiva no sentido contrário ao da realidade. Mas se o agente procede da dúvida, nenhuma escusa poderá invocar, pois gravitou na órbita do dolo eventual"

Passemos agora à análise da legítima defesa putativa, que é também decorrente de um êrro de fato essencial ou substancial, como condição sine qua non do evento. Ela se verifica quando alguém se supõe em face de uma agressão iminente ou atual e injusta, embora tal não se dê, realmente, mas o agente foi levado a essa conclusão por êrro subjetivo, também invencível e inevitável. A situação objetiva foi de tal ordem que o ofendido supôs uma situação muito pior do que era na realidade e reagiu 
de boa fé, sujeito às aparências enganosas. João discute ardorosamente com Pedro, quando êste faz um gesto suspeito, como de quem vai sacar sua arma. João então, inopinadamente, com receio de ser morto, tira seu revolver da cinta e o desfecha contra aquêle que supõe ser o seu agressor. Pedro morre, em consequência dos ferimentos recebidos; mas a Polícia constata que êle estava desarmado!

Os advogados no juri têm se aproveitado, abusivamente, da legítima defesa putativa ou subjetiva. É óbvio que para ela ser aceita terá de ser a consequencia de um êrro de percepção invencível e bem comprovado. Admitíla levianamente, a qualquer pretexto, é coonestar homicídios, às vêzes bárbaros. Infelizmente, a instituição democrática do júri, que é soberano em suas decisões, em face da própria Constituição Federal, tem abusado - sobretudo no interior do país - dêsses veredictos de favor ou de proteção, estimulando a prática de assassinatos. Achamos que o júri não devia ter êsse poder absoluto, de julgar até contra as provas dos autos, pois que isto não deixa de ser uma subversão da justiça, que os tribunais deviam ter o direito de corrigir. Êstes se vêem apenas na contingência de anular os processos, mandando o reu a novo júri, mas a absolvição iníqua quase sempre se repete, gerando a insegurança em nosso sertão. É preciso que a Justiça Pública se torne cada vez mais independente da influência malsã da política facciosa, que interfere no corpo de jurados, levando-os a proferir decisões absolutórias juridicamente infundadas e aumentando o amibente de insegurança em nosso interior, onde geralmente impera a vontade de grupos, que aplaudem a violência como norma de ação ou como demonstração de um mandonismo ainda primitivo e quase selvagem. Outros jurados, levados por um sentimento cristão mal compreendido, acham que devem absolver sempre, o que importa em estimular o crime, que deve ser reprimido, através de conde- 
nações justas, para a própria garantia da ordem social. 0 fato é que a instituição do júri tem se demonstrado cada vez mais ineficiente e perniciosa, sobretudo no interior brasileiro, por circunstâncias várias, mas perdura consagrada na Constituição como êrro da tradição ou como fruto do sentimentalismo exagerado dos brasileiros, sempre prontos a absolver, esquecidos da extensão do dano que um homicídio acarreta à família e ao Estado.

O Direito Penal é uma bela ciência, encantadora para o estudo em nossas academias, sobretudo devido à filosofia, cuja análise se entremeia a seus institutos, mas na prática, geralmente, a situação é muito diversa, em virtude das falhas de nossa justiça, consequência sobretudo dessa instituição constitucional do júri, que se não tem adaptado ao interêsse público, nem às altas finalidades da Criminologia, que jamais poderia doutrinar a absolvição sistemática.

A legitima defesa putativa, entretanto, não podia deixar de ser consagrada em nosso direito constituido, porque há casos, embora raros, em que ela se verifica. Existe ainda a conduta resultante de um êrro de fato substancial, que importa em um estado de necessidade putativo. Êle isenta ainda o agente de responsabilidade penal. Figuremos um alarme falso em casa de diversão, em um cinema, por exemplo. Todos correm para a porta, supondo haver um perigo iminente. Algumas pessoas são pisadas e saem feridas. Uma delas, que era cardíaca, vem a falecer. Não é de se cogitar, nesse caso, de responsabilidade criminal, a não ser por parte daquêle que deu o alarme falso, que se pode ter conduzido culposamente, ou seja, por imprudência. plifica :

José Frederico Marques, em sua citada obra, ainda exem-

"É possível êrro de fato em relação às justificativas do art. 19, n. ${ }^{\circ}$ III, do Código Penal. 0 indivíduo que prende em flagrante delito a uma pessoa que não havia pra- 
ticado nenhum crime, pode ter agido por fôrça de êrro de fato, confundindo o detido com aquêle que realmente praticou o delito. Neste caso, o constrangimento ilegal (art. 146 do Código Penal) não é punível, porque houve êrro sôbre a situação de fato que permitia efetuar a prisão (Cod. do Proc. Penal, art. 301). 0 mesmo sucederia no caso do soldado que, em ação de guerra, matasse a um companheiro, confundindo-o, à distância, com um inimigo".

Êste último exemplo foi tirado de Sebastian Soler, "Derecho Penal Argentino", v. II, pag. 90.

Mas, conforme já frisamos, o êrro de fato só exclui a culpabilidade, quando fôr essencial; desde que seja acidental, secundária ou acessória, a conduta do agente continua incriminável.

Por consequência, tanto no error in persona, quanto na aberratio ictus, é dolosa a conduta do agente e êle é responsável pelo evento.

Quanto ao êrro com relação à pessoa da vítima, o art. 17 $\S 10^{\circ}$ do Código Penal é de uma clareza meridiana. Se uma pessoa atira em Jorge, supondo que é Paulo, sua conduta é criminosa. $O$ êrro aí é acidental ou secundário, a intenção de delinquir foi manifesta, pouco importando o engano.

O Estado tem o direito e o dever de punir qualquer conduta perversa, configurada na fonte única do Direito Penal, que é a lei; para êle tanto vale a vida de Paulo como a de Jorge, pois todos tem os mesmos direitos e são iguais perante a sua lei.

Realmente, é vedado matar alguém; o êrro quanto à pessôa da vítima é indiferente, pois o Estado procura resguardar a vida humana, seja de quem fôr. Entretanto, em casos de error in persona, não se consideram as condições ou qualidades da vítima, senão as da pessoa contra quem o agente queria praticar o crime. É o que prescreve a parte final do art. $17 \S 3 .^{\circ}$ 
Por outro lado, a aberratio ictus, isto é, o desvio da trajetória da bala, por qualquer circunstância, desde que ofenda outrem, também não isenta de responsabilidade penal o delinquente, que terá praticado um crime doloso. Às vezes o fato é motivado por êrro de pontaria (inabilidade do agente) ou porque alguém lhe bateu no braço, na hora do detonar. Seja qual fôr o motivo, o êrro aí é considerado como acidental, inescusável, irrelevante.

O Código Penal prevê a hipótese, denominando-a "êrro na execução". (art. 53). E se, com os mesmos disparos, o delinquente mata um e fere outro, estranho ào drama, dá-se aí um concurso formal de delitos, aplicando-se no caso o art. $51 \S 1 .^{\circ}$ Ambos êsses crimes serão considerados dolosos.

A Exposição de Motivos, do então Ministro Francisco Campos, assim se manifesta sôbre o assunto:

"No art. 53 é disciplinada a aberratio ictus seu actus, que eventualmente pode redundar num concurso de crimes. $O$ projeto vê na aberratio uma universidade substancial de crime, ou seja, um só crime doloso (absorvida por êste a tentativa contra a pessoa visada pelo agente), ou no caso de ser também atingida a pessoa visada, um concurso formal de crimes. Na primeira hipótese, o êrro sôbre o direito material (e não sôbre o objeto jurídico) é acidental e, portanto, irrelevante. $\mathrm{Na}$ segunda hipótese, a solução dada se justifica pela unidade da atividade criminosa".

Agora vejamos a aberratio criminis ou o resultado diverso do pretendido, previsto pelo art. 54 do Código Penal.

Diz ainda a Exposição de Motivos:

"Em seguida à aberratio persona in personam, é prevista a hipótese da aberratio em objetos jurídicos de espécie diversas. Tal é o caso figurado por Maggiore, de quem, querendo quebrar a janela alheia com uma pedrada, fere um transeunte, ou vice-versa. Aqui, a solução é a seguinte: se ocorre o resultado diverso do que foi querido pelo agente, responde êste por culpa, se o fato é pre- 
visto como crime culposo; se ocorre igualmente o resultado querido pelo agente, aplica-se a regra do concurso formal (identificando-se na espécie um concurso formal de crime doloso e culposo)".

José Frederico Marques, em sua recente obra "Curso de Direito Penal"; fala ainda em outra espécie de aberratio, a aberratio causae. Diz êle:

"A doutrina cogita de uma terceira espécie de aberratio, a que Carnelutti se refere com a denominação de aberratio causae. Ela ocorre quando o fluxo causal se desenvolve de modo diferente daquele que o agente havia previsto, sem que o resultado deixe de ocorrer. Tício atira uma criança ao rio para que morra afogada; todavia, na queda, a vítima vai ao encontro de uma pedra e sofre fratura na base do crâneo, que vem a ser a causa mortis. Em tal hipótese, é evidente que o sujeito ativo deve responder por crime de homicídio, da mesma forma que se a morte houvesse ocorrido por afogamento, pois, como lembra Antolisei, é indiferente, para a configuração do homicídio, que a morte tenha sido causada desta ou daquela forma.

"Hipótese mais complexa se verifica quando o agente supõe haver consumado o crime, e o evento no entanto se realiza em ação sucessiva, destinada a ocultá-la. Dá-se, do caso, o seguinte exemplo: A. desfecha em B. um tiro de arma de fogo. Êste, assustado, perde os sentidos e cai como se estivesse morto. A., supondo-o sem vida, para encobrir o crime, atira a vítima ao rio. Esta morre por asfixia. Falam os antigos criminalistas, neste caso, de um dolo generalis, e admitem a responsabilidade do agente a título de dolo, por um só delito. Para Costa e Silva o problema é diveras complicado e "ainda não foi devidamente aprofundado". Em nosso entender, conclui José Frederico Marques, é certa a solução de Antolisei e da doutrina moderna. Diz o escritor citado o seguinte: "Atualmente a doutrina prevalente descobre no fato dois crimes, e precisamente o concurso de uma tentativa com crime culposo, por considerar que no mesmo fato se en- 
contram duas atividades distintas, que são acompanhas de estados psíquicos diversos".

Data venia, discordamos do ilustrado professor paulista. Houve no caso, sem dúvida, duas atividades intelectuais diversas, mas guiadas pela mesma intenção, a de assassinar uma determinada pessoa. Os atos fôram continuados, porém visando uma só vítima, a quem se pretendia matar e que, afinal, veio a morrer.

Suponhamos que a referida pessoa despertasse nágua, e como bom nadador, conseguisse fugir. Não teria havido uma só tentativa de homicídio? Por que então, no caso de morte, figurar dois crimes, quando em verdade, foi só uma a intenção delituosa? Preferimos assim ficar com o dolo generalis dos antigos, que é menos casuistico ou cheio de complexidades mentais, porém muito mais lógico...

Além disso, o crime maior absorve o menor. Quando alguém fere e em seguida mata um cidadão, responde apenas por crime de homicídio. No caso figurado, houve a morte e a intenção dolosa de matar; pouco importa que tenha havido antes, apenas, uma tentativa, se o resultado final foi o homicídio. Por consequência, entendemos que o criminoso deve responder aí pelo crime previsto no art. 121 de nosso Código Penal, embora duas tivessem sido suas atividades delituosas, ambas vișando o mesmo resultado - a morte da vítima - que afinal foi conseguido. Quando, com a mesmo intenção e pretendendo o mesmo resultado, o criminoso pratica atos sucessivos e imediatos, êles incorporam ao iter criminis e, se o delinquente atinge o objetivo visado, sómente pelo crime que pretendeu realizar e que consumou é que poderá, justamente, responder.

Para finalizar, faremos ligeiras apreciações sôbre o $\S 2 .^{\circ}$ do art. 17 do Código Penal, que prescreve:

"Responde pelo crime o terceiro que determinou o êrro".

Essa interveniência ou determinação do terceiro pode ser dolosa ou culposa.

Se houve preordenação no êrro, isto é, se êle foi orientado consciente e voluntáriamente, a intervenção de terceiro na fi- 
gura criminal é dolosa. Mas se o terceiro agiu apenas por imprudência, negligência ou imperícia, e não teve a intenção de motivar o delitto, responderá por crime culposo.

A prova colhida no processo esclarecrá o fato. A prática do Direito Penal resume-se na colheita das provas, que vão caracterizar a natureza do delito. O Direito Judiciário Penal é um complemento indispensável ao substantivo criminal ou Direitto Penal, porque o processo busca a verdade jurídica, fim colimado pelo Estado.

Há interêsse geral de que se faça justiça, mas esta só é conseguida pelo esfôrço conjugado das partes litigantes e do Juiz que, modernamente, é o orientador do processo.

O magistrado, encarnando o Poder Judiciário, representa o Estado, que tem o supremo escôpo de efetivar o direito, prevenindo, reprimindo ou dando a cada um o que é seu :

Não é para outro mistér que o Estado se aparêlha em materia criminal, com a sua Policia, para prevenir os delitos, ou para investigá-los; com o Ministério Público, que denuncia e acusa, defendendo os interêsses da sociedade, e com o Juiz, que diretamente o representa e que deve decidir com serenidade e critério, à luz da melhor doutrina. Assim, o estudo de cada caso concreto deve ser feito ponderada e criteriosamente, olhando o magistrado para o interêsse individual, mas sem esquecer também o social. $\mathrm{E}$ se alguma pena tiver de ser aplicar, medida coercitiva imperiosa, que restringe o direito à liberdade, é necessário que o seja de modo exato, justo ou acertado, pois que a sanção punitiva deve ter por finalidade, não a vingança social, mas a segregação e a readaptação do elemento nocivo à coletividade, de tal sorte que êle possa vir a ser futuramente, quando egresso da penitenciária, um elemento útil ao Estado ou à comunhão social. A pena é uma espécie de remédio enérgico aplicado ao criminoso, que é um doente ou um pervertido, buscando sua cura ou sua readaptação ao convívio social. Os maiores celerados não poderão deixar de ser tratados com certa humanidade, pois afinal não tiveram culpa de ter nascido assim. São sêres humanos, dignos de assistência e, se não 
conseguirem o restabelecimento psíco-somático, deverão continuar segregados em nosocômios judiciários, onde não lhes deve faltar o amparo do Estado, que o gerou no seu próprio caldo de cultura...

Como quer que seja, a sentença criminal é um decreto judiciário de transcendental importância, devendo ser exarada depois de um estudo acurado da espécie, afim de que a justiça se torne lógica e efetiva; mas para isto, é imprescindível que o Estado se muna, cada vez mais, dos melhores elementos, dos mais científicos e eficientes, à sua efetivação execução.

É preciso que aperfeiçoemos sempre nosso aparelhamento judiciário; êle é composto, sobretudo, do elemento humano, que deve aprimorar, através da ponderação e do estudo, a consciência de suas responsabilidades.

O juiz então - em face da dose maior de imputabilidade moral que lhe assiste para com a coletividade - ao exarar sua sentença, deve pesar bastante sua noção de certeza jurídica, convicto de que êle encarna o Estado e certo ainda de que uma das coisas mais dolorosas é a injustiça. Temos para nós que a magistrautra é um sacerdócio. A ela deverão dirigir-se ou melhor, nela deverão sómente ingressar, aquêles que fôrem calmos e serenos, capazes de se sobreporem às paixões ambientes.

A missão do Juiz é tão sagrada, que êle não pode fazer idéia de quanto cai, quando se apaixona... Témis é apresentada a olhos fechados às injunções do meio amibente e assim 0 juiz deve esforçar-se para dignificar, cada vez mais, o cargo que ocupa. Confiamos nos moços de hoje, afim de que elevem amanhã, ainda mais, nossa magistratura, que se agora é boa, esperamos, sinceramente, que venha a ser ótima. Outrotanto em relação ao advogado, que não deve pensar apenas em ganhar dinheiro. 0 "vil metal" é necessário à luta pela vida, mas há qualidades mais nobres do espírito que não podem ser desprezadas. Para que traçar regras a respeito? Elas estão em nossa própria consciência e nós sabemos, perfeitamente, quando estamos dignificando a profissão e servindo à Justiça! 